\title{
A retrospective feasibility study of biweekly docetaxel in patients with high-risk metastatic castration-naïve prostate cancer
}

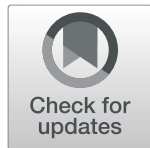

Sang Eun Yoon ${ }^{1}$, Youjin Kim¹, Jangho Cho', Minyong Kang², Hyun Hwan Sung ${ }^{2}$, Hwang Gyun Jeon², Byoung Chang Jeong ${ }^{2}$, Seong $\| \mathrm{Seo}^{2}$, Seong Soo Jeon ${ }^{2}$, Hyun Moo Lee ${ }^{2}$, Han Yong Choi ${ }^{2,3}$, Su Jin Lee ${ }^{1}$ and Se Hoon Park ${ }^{1 *}$ (D)

\begin{abstract}
Background: Results from randomized phase III trials have shown that thrice-weekly docetaxel added to androgendeprivation therapy (ADT) has a significant impact on the survival of patients with metastatic castration-naïve prostate cancer (mCNPC) and established early chemotherapy as part of the standard of care for high-risk disease. Controversy remains, however, because some patients experience critical toxicities related to docetaxel. The purpose of the current study was to evaluate the feasibility and adverse events of biweekly-administered docetaxel in patients with previouslyuntreated, high-risk mCNPC.
\end{abstract}

Methods: The study included 35 consecutive patients with high-risk mCNPC who received ADT plus docetaxel $40 \mathrm{mg} /$ $\mathrm{m}^{2}$. Oral prednisone $5 \mathrm{mg}$ twice daily was also given. Treatment was repeated every two weeks for up to 12 cycles or until disease progression or unacceptable toxicity occurred. High-risk was defined as bone metastases beyond axial skeleton and/or visceral disease.

Results: The included patients' median age was 68 years (range: 31-86years) and 17 (49\%) had visceral metastases. Biweekly docetaxel was generally well-tolerated; the most commonly observed adverse events, considering those of all grades, included alopecia (74\%), nail changes (42\%), and constipation (31\%). Hematologic adverse events were infrequent, and no patient received hematopoietic growth factors. One patient died after the fourth cycle due to respiratory failure, which occurred as a complication of pneumonia. Among the 35 patients, 28 completed the planned 12 cycles of biweekly docetaxel. Prostate-specific antigen response (>50\% decrease from baseline) was recorded in 33 patients (94\%), and the radiologic response rate was 49\%. Median progression-free survival was 13.6 months (95\% confidence interval: 6.7-20.4).

Conclusion: ADT plus biweekly-administered docetaxel appeared to be tolerated and effective in patients with high-risk mCNPC.

Keywords: Castration-naïve prostate cancer, Docetaxel, Biweekly

\footnotetext{
* Correspondence: hematoma@skku.edu

${ }^{1}$ Division of Hematology-Oncology, Department of Medicine, Samsung

Medical Center, Sungkyunkwan University School of Medicine, 81 Irwon-ro,

Gangnam-gu, Seoul 06351, South Korea

Full list of author information is available at the end of the article
}

(c) The Author(s). 2019 Open Access This article is distributed under the terms of the Creative Commons Attribution 4.0 International License (http://creativecommons.org/licenses/by/4.0/), which permits unrestricted use, distribution, and reproduction in any medium, provided you give appropriate credit to the original author(s) and the source, provide a link to the Creative Commons license, and indicate if changes were made. The Creative Commons Public Domain Dedication waiver (http://creativecommons.org/publicdomain/zero/1.0/) applies to the data made available in this article, unless otherwise stated. 


\section{Background}

Prostate cancer is one of the greatest growing cancers in Korea, with an estimated 9785 new cases and 1667 deaths occurring in Korea in 2014 [1]. For patients with metastatic or advanced disease, androgen-deprivation therapy (ADT), which includes bilateral orchiectomy or medical castration with gonadotropin-releasing hormone (GNRH) agonists, can provide palliation of symptoms and prolong survival [2]. If a patient develops castrationresistant prostate cancer (CRPC), docetaxel is regarded as the standard first-line chemotherapy regimen from the results of two randomized clinical trials [3, 4].

Docetaxel is commonly administered at a dose of 75 $\mathrm{mg} / \mathrm{m}^{2}$ every 3 weeks established by the results from the TAX-327 study [5, 6], in which once every 3 weeks docetaxel (median: 19.2 months, $95 \%$ CI, 17.5 to 21.3 months) conferred a definite survival benefit over weekly docetaxel for 3 weeks (median: 17.8 months, 95\% CI, 16.2 to 19.2 months).

In Asian countries, there was better survival benefit in every 3 weeks administration(12.5 months) than every week administration (8.0 months). No grade 3 or 4 neutropenia was showed in once weekly for 3 weeks, but $\mathrm{Gr}$ $3 / 4$ neutropenia was observed more frequently about $75 \%$ of patients with CRPC who were treated with once every 3 weeks docetaxel [7]. Based on previous studies, a pharmacokinetics study conducted in Japan [8] and consideration of efficacy and toxicities in the management of solid tumors in a palliative setting [9], docetaxel is most commonly administered in Korea and Japan at a lower dose (i.e., $60 \mathrm{mg} / \mathrm{m}^{2}$ every 3 weeks).

An additional option to prevent docetaxel-related hematologic toxicity is to use other administration schedules, such as weekly or biweekly regimens. On the side of this approach, biweekly administration of docetaxel $50 \mathrm{mg} / \mathrm{m}^{2}$ showed a better time-to-failure (TTF; median: 5.6 months vs. 4.9 months; $P=0.014$ ) than thrice-weekly docetaxel [10]. As expected, the biweekly regimen was better tolerated than the thrice-weekly docetaxel regimen, and importantly, efficacy was not compromised. In our own retrospective study [11], we showed that a docetaxel $40 \mathrm{mg} / \mathrm{m}^{2}$ biweekly regimen was appropriate and well-tolerated in Korean patients with CRPC.

Although surgical or medical castration is considered standard treatment in castrate-naïve prostate cancer (CNPC), some patients with extensive metastatic (i.e., high-risk) disease at diagnosis, including visceral or bone involvement beyond the axial skeleton, have shorter survival times [12]. It is not enough to start standard hormone castration treatment alone to high tumor volume at CNPC diagnosis. The previous randomized phase III trials were conducted using either six or nine cycles of docetaxel $75 \mathrm{mg} / \mathrm{m}^{2}$ every 3 weeks in the CNPC setting
[13-15]. Their results led to early change to ADT in high-risk CNPC in most guidelines published by the oncology societies $[16,17]$. Supposedly, the new standard therapy should only be applied in patients fit enough to receive docetaxel and tolerate the associated side effects. Based on these considerations, from October 2013, we adopted a biweekly low-dose docetaxel regimen $(40 \mathrm{mg} /$ $\mathrm{m}^{2}$ every 2 weeks) as an institutional standard chemotherapy regimen for patients with chemotherapy-naïve CNPC. The present study was conducted to evaluate the tolerability of the regimen and to obtain feasibility data in anticipation of performing a prospective, formal phase II study.

\section{Methods}

We retrospectively collected and reviewed the medical records of 35 men with metastatic CNPC who were consecutively treated with biweekly docetaxel and ADT as first-line therapy between October 2015 and December 2016. In the present study, we included the patients with histologically-confirmed adenocarcinoma of the prostate and naïve to both ADT and chemotherapy. The other eligibility criteria consisted of an Eastern Cooperative Oncology Group (ECOG) performance status of 0 or 1, radiologic and clinical evidence of high-risk metastatic disease for which there was no curative treatment available, and acceptable major organ functioning to receive chemotherapy. High-risk was defined as bone metastases beyond the axial skeleton and/or visceral disease, regardless of prostate-specific antigen (PSA) level.

The choice of early docetaxel was determined by a multidisciplinary urologic oncology team composed of urologists, radiologists, pathologists, radiation oncologists, and medical oncologists. The study protocol was approved by the Samsung Medical Center (Seoul, Korea) Institutional Review Board, and all patients provided written informed consent prior to undergoing docetaxel chemotherapy.

\section{Treatment}

Our medical center standard chemotherapy for CRPC has been a biweekly docetaxel $40 \mathrm{mg} / \mathrm{m}^{2}$ regimen [11], corresponding to a dose intensity of $20 \mathrm{mg} / \mathrm{m}^{2} /$ week (equivalent to $60 \mathrm{mg} / \mathrm{m}^{2}$ every 3 weeks). Docetaxel was administered intravenously over 1 hour on day 1 with dexamethasone and antiemetics. Oral prednisolone $5 \mathrm{mg}$ was administered twice daily from day 1 and continued throughout treatment. Supportive care, including the administration of blood products, bisphosphonates, and the use of analgesics, was given if judged appropriate by the treating physicians. Prior to initiation of the first dose of docetaxel, a complete history was taken from each patient. In addition, complete blood counts, serum chemistry analyses, chest X-rays, bone scans, and computed 
tomography (CT) scans of all involved sites were performed. Patients were seen every 2 weeks; during these visits, a brief history was taken; a physical examination was performed; and adverse events, blood counts, and PSA level were assessed. Treatment was repeated on an outpatient basis and continued until objective disease progression, unacceptable toxicity, patient refusal, or up to 12 cycles. Throughout the treatment period, ADT with GNRH agonists was given to all participants, except those who underwent surgical castration. Radiologic responses were evaluated every 8 weeks by bone scan, chest and abdominopelvic $\mathrm{CT}$, or the same tests that were used for initial tumor staging. Adverse events were collected and graded according to the National Cancer Institute's Common Terminology Criteria for Adverse Events version 4.

\section{Statistical analysis}

The evaluation of toxicity was the primary endpoint for the study, and myelosuppression, specifically grade 3 or 4 neutropenia and febrile neutropenia, was considered to be the dose-limiting toxicity. Other endpoints included a PSA response, defined as a $\geq 50 \%$ decline in PSA level from baseline with no clinical or radiologic evidence of disease progression, overall survival (OS), and progression-free survival (PFS). PFS was defined as the time from the first administration of docetaxel to the date of disease progression (PSA or radiologic progression) or death. PSA progression was defined as an increase $\geq 25 \%$ and $\geq 2 \mathrm{ng} / \mathrm{mL}$ after 12 weeks according to the Prostate Cancer Working Group 2 criteria [18]. PFS and $O S$ were calculated using the Kaplan-Meier method. All analyses were performed using $\mathrm{R}$ for Windows, version 2.11.1 (http://www.r-project.org; R Core Team, Vienna, Austria).

\section{Results}

The baseline patient characteristics of 35 patients who were registered between October 2015 and December 2016 are listed in Table 1. Their median age was 68 years (range: $31-86$ years), and $71 \%$ had symptomatic (i.e., ECOG performance status of 1) disease. The most commonly involved metastatic sites were bone (97\%) and lymph nodes (91\%), and 17 participants (49\%) had visceral metastases. ADT was initiated within 1 month of starting docetaxel in all patients in combination with leuprolide (57\%), goserelin (40\%), or degarelix (3\%).

The included patients received a total of 1483 cycles of biweekly docetaxel (median: 12, range: 1-12). Three patients discontinued treatment after the first cycle, two due to toxicity or withdrawal and one due to disease progression. Docetaxel was delayed in 17 cycles (1\%), and dose reduction was required in five patients (14\%). As a dose intensity of docetaxel $20 \mathrm{mg} / \mathrm{m}^{2} /$ week was planned, the relative dose intensity was 98\% [95\%
Table 1 Patient characteristics

\begin{tabular}{|c|c|c|}
\hline & No. & $\%$ \\
\hline \multicolumn{3}{|l|}{ Age, years } \\
\hline Median (range) & $68(31-86)$ & \\
\hline \multicolumn{3}{|l|}{ Disease status } \\
\hline Metastatic at diagnosis & 31 & 89 \\
\hline Recurrent & 4 & 11 \\
\hline \multicolumn{3}{|l|}{ Gleason score } \\
\hline 6 & 1 & 3 \\
\hline 7 & 5 & 14 \\
\hline 8 & 13 & 37 \\
\hline 9 & 12 & 34 \\
\hline 10 & 4 & 11 \\
\hline \multicolumn{3}{|l|}{ Initial PSA, ng/mL } \\
\hline Median (range) & \multicolumn{2}{|l|}{$330.08(4-50,000)$} \\
\hline \multicolumn{3}{|l|}{ Type of metastases } \\
\hline Bone and/or lymph nodes only & 18 & 51 \\
\hline Visceral & 17 & 49 \\
\hline \multicolumn{3}{|l|}{ Metastatic site } \\
\hline Lymph node & 32 & 91 \\
\hline Bone & 34 & 97 \\
\hline Lung & 16 & 46 \\
\hline Liver & 4 & 11 \\
\hline \multicolumn{3}{|l|}{ ECOG performance status } \\
\hline 0 & 10 & 29 \\
\hline 1 & 25 & 71 \\
\hline
\end{tabular}

PSA prostate-specific antigen, ECOG Eastern Cooperative Oncology Group Because the patients could have metastases at multiple sites, the total number of metastases cases is greater than the number of patients

confidence interval (CI): 86-104]. Biweekly docetaxel showed manageable toxicities including all grades (Table 2). The most ordinary adverse events were alopecia (74\%), nail changes (42\%), and constipation (31\%). Hematologic adverse events presented rarely. There were five patients required blood transfusion due to anemia and/or thrombocytopenia, but they did not receive hematopoietic growth factors. One patient died of respiratory failure induced pneumonia complication after completing the fourth cycle chemotherapy.

There was no complete clinical response in the current study. 31 patients evaluated for radiologic responses and 17 patients (55, 95\% CI: 46-64) presented partial responses. and 10 patients achieved stable disease. Finally, $87 \%$ of the overall patients obtained adequate disease control.

Thirty-three patients (94\%) demonstrated PSA response (> 50\% decrease from baseline), and $49 \%$ patients appeared radiologic response. Median PFS was 13.6 months (95\% CI: 6.7-20.4). Median OS was not reached, but the OS rate at 1 year was identified as $75 \%$ (Fig. 1). 
Table 2 Maximum grade of toxicities per patient

\begin{tabular}{lll}
\hline & Grades 1/2 & Grades 3/4 \\
& N (\%) & N (22.9) \\
\hline Anemia & $6(17.1)$ & $4(11.4)$ \\
Neutropenia & $4(11.4)$ & 0 \\
Thrombocytopenia & $26(74.3)$ & $1(2.9)$ \\
Alopecia & $6(17.1)$ & 0 \\
Fatigue & $4(11.4)$ & 0 \\
Nausea & $5(14.3)$ & 0 \\
Anorexia & $8(22.9)$ & 0 \\
Peripheral neuropathy & $7(20)$ & 0 \\
Stomatitis & $3(8.6)$ & 0 \\
Diarrhea & $11(31.4)$ & $1(2.9)$ \\
Constipation & $9(25.7)$ & 0 \\
Skin & $15(42.9)$ & 0 \\
Nail changes & & 0 \\
\hline
\end{tabular}

\section{Discussion}

There are newly developed numerous treatment options for advanced prostate cancer, but it is not yet possible to replace all of the docetaxel [17]. The standard docetaxel regimen $\left(75 \mathrm{mg} / \mathrm{m}^{2}\right.$ every 3 weeks plus prednisone) should significantly improve overall survival for long time in metastatic CRPC, but more often grade 3-4 adverse events. In the current study, we reported that docetaxel $40 \mathrm{mg} / \mathrm{m}^{2}$ every 2 weeks plus prednisolone was similar in efficacy and manageable toxicities compared to previous studies.

Docetaxel administrated $75 \mathrm{mg} / \mathrm{m} 2$ every 3 weeks is mostly used at the standard of chemotherapy of mCRPC. However, therapy-related adverse effects and treatment related mortality were prevalent in elderly and fragile patients to receive standard regimen. Although the response of docetaxel $75 \mathrm{mg} / \mathrm{m} 2$ every 3 weeks schedule was favorable, it did not show the good overall survival for these patients. [19].

In a retrospective study, we evaluated the feasibility of biweekly docetaxel $40 \mathrm{mg} / \mathrm{m} 2$ and compared with 75 $\mathrm{mg} / \mathrm{m} 2$ every 3 weeks for $\mathrm{mCRPC}$. Their median age was 68 years (range, 52-84). The patients received biweekly docetaxel $40 \mathrm{mg} / \mathrm{m} 2$ presented similar TTP $(5.0$ months vs 4.2 months, $p$-value $=0.530$ ) and minor incidence of Gr 3/4 adverse events. This result exhibited one of the treatment schedule options for mCRPC [11].

There were no comparable studies of biweekly docetaxel $40 \mathrm{mg} / \mathrm{m} 2$ and $75 \mathrm{mg} / \mathrm{m} 2$ every 3 weeks for mCNPC. In the CHAARTED study, the researchers compared the efficacy and toxicity of docetaxel (at a dose of $75 \mathrm{mg} / \mathrm{m}^{2}$ every 3 weeks for 6 cycles) plus ADT and ADT alone of $790 \mathrm{mCNPC}$ patients. The docetaxel plus ADT regimen demonstrated better outcomes than ADT alone $(57.6$ months vs. 44.0 months; $P<0.001)$ in patient with $\mathrm{mCNPC}$. The current outcome was not equally comparable with the CHAARTED due to the follow-up period was shorter, as so we need a long-term follow-up period to present the outcome including OS. However, adequate response rate reached $87 \%$ even in the short observation period, we considered one of the treatment options.

We already know that the high tumor burden is a poor prognostic factor. Each clinical study had also dealt with the correlation survival and high tumor burden. In the subgroup analysis from the CHAARTED study, a high volume of metastases was defined by the presence of visceral metastases or four or more bone lesions with at least one beyond the vertebral bodies and pelvis. There were $57(14.4 \%)$ patients with visceral metastasis who had poor median OS (49.2 months) than in all CNPC patients (57.6 months) [13, 14]. In the GETUG-AFU15 study, the median OS was approximately 62.1 months

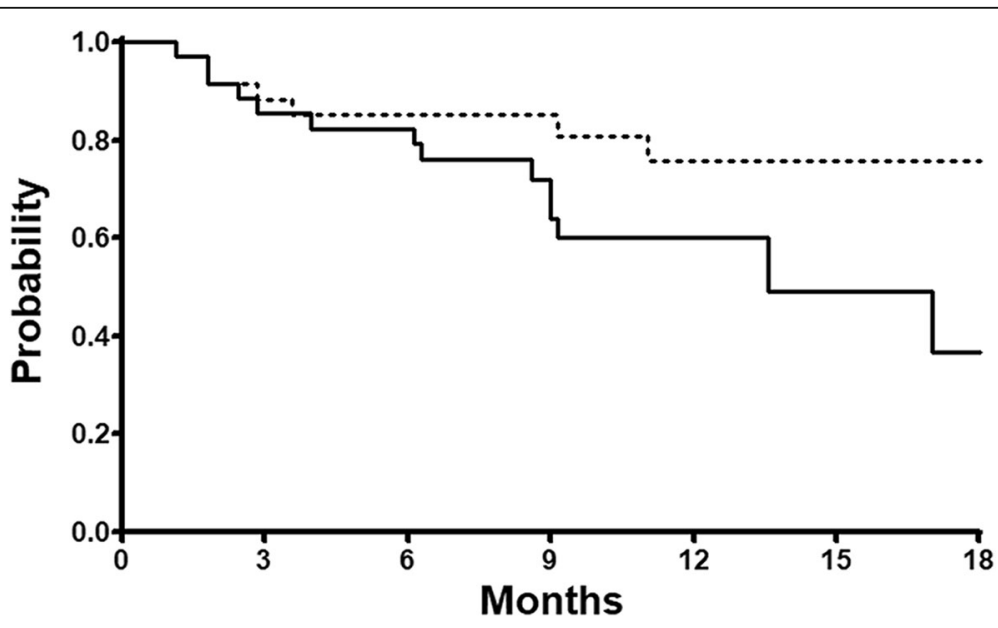

Fig. 1 Kaplan-Meier curve for PFS (solid line) and OS (dotted line) 
in the mCNPC patients, and less than 36 months in the $\mathrm{mCNPC}$ patient with high-volume, high-risk disease [14].

In current study, we included that all patients had high-volume CNPC such as visceral metastasis (49\%) and bone metastasis (51\%). The result (median PFS: 13.6 months, 95\% CI: 6.7-20.4) was not as bad as expected from high risk. However, it is limited in interpretation of the PFS because of small sample size and short follow up period. Based on recent randomized trials [13-15] and our data, the addition of docetaxel to ADT is recommended for patients with high-risk, metastatic CNPC who are medically-fit enough to tolerate docetaxel.

In the CHAARTED, the total dosage of docetaxel 75 $\mathrm{mg} / \mathrm{m}^{2}$ every 3 weeks for 6 cycles was $450 \mathrm{mg}$, and the period of administration was 18 weeks. Similarly, the total dosage of the $40 \mathrm{mg} / \mathrm{m}^{2}$ every two-week regimen was $480 \mathrm{mg}$, and the period of administration was 24 weeks. There was a little difference in docetaxel dosage or administration period between the two regimens. Nevertheless, it showed a different pattern of drug toxicities between the two studies. Approximately $12.1 \%$ of patients in the CHAARTED had grade 3 or 4 neutropenia and $6.1 \%$ had grade 3 or 4 febrile neutropenia. $[13,14]$. In present study, the most common hematologic toxicity of any grade was anemia $(n=12)$, and grade 3 or 4 hematological adverse events occurred infrequently. There was no big distinctness in the dose and the toxicity was lower in $40 \mathrm{mg} / \mathrm{m}^{2}$ every two-week regimen. So, we could suggest A as other administration schedules on these results.

The major limitations of our retrospective study include small sample size and lack of a control arm to better define differences between biweekly dosing and standard dosing in this population. Further accumulation of cases with longer follow-up periods is necessary. Within the limitations of our study, we demonstrated that early chemotherapy with biweekly docetaxel regimen resulted in tolerability and activity in patients with high-risk CNPC.

ADT plus biweekly-administered docetaxel appeared to be tolerated and effective in patients with high-risk mCNPC comparable with CRPC. Our results suggest that a biweekly docetaxel chemotherapy regimen is considered to have manageable toxicities and to yield acceptable results compared to a thrice-weekly docetaxel regimen.

\section{Conclusion}

In conclusion, ADT plus biweekly-administered docetaxel appeared tolerable toxicities and similar efficacy compared with standard thrice-weekly docetaxel. From this result, we could suggest that docetaxel $40 \mathrm{mg} / \mathrm{m} 2$ biweekly regimen is an additional treatment option for mCNPC.

\section{Abbreviations}

ADT: Androgen-deprivation therapy; CNPC: Castration-naïve prostate cancer; CRPC: Castration-resistant prostate cancer; GNRH: Gonadotropin-releasing hormone

Acknowledgements

Abstract of this manuscript is presented in annual meeting of ASCO 2018

\section{Funding}

No funding was obtained for this study.

\section{Availability of data and materials}

The information supporting the conclusions of this article is included within the article. Further information can be obtained upon request.

\section{Authors' contributions}

SHP conceived and designated the study; SEY, SEP, YJK and JJC participated in its design and coordination and helped to draft the manuscript. HGJ, HYC and SJL performed relevant operations and collected patients' data; MYK and HHS helped acquisition and interpretation of data; SEP and SHP participated in the statistical analysis; BCJ, SLS, SSJ and HML critically revised the manuscript; All authors read and approved the final manuscript.

\section{Ethics approval and consent to participate}

This research is strictly retrospective and involving the collection of existing data and records. This study was approved by the Institutional Review Board of Samsung Medical Center (Seoul, Korea; IRB_2017-01-005) and written informed consent was provided by all patients prior to starting chemotherapy, according to our institutional standards.

Consent for publication

Not applicable.

\section{Competing interests}

The authors declare that they have no competing interests.

\section{Publisher's Note}

Springer Nature remains neutral with regard to jurisdictional claims in published maps and institutional affiliations.

\section{Author details}

${ }^{1}$ Division of Hematology-Oncology, Department of Medicine, Samsung Medical Center, Sungkyunkwan University School of Medicine, 81 Irwon-ro, Gangnam-gu, Seoul 06351, South Korea. ²Department of Urology, Samsung Medical Center, Sungkyunkwan University School of Medicine, Seoul, South Korea. ${ }^{3}$ Department of Urology, Kangbuk Samsung Hospital, Sungkyunkwan University School of Medicine, Seoul, South Korea.

Received: 22 November 2018 Accepted: 17 April 2019

Published online: 03 May 2019

\section{References}

1. Jung KW, Won YJ, Oh CM, Kong HJ, Lee DH, Lee KH, et al. Cancer statistics in Korea: incidence, mortality, survival, and prevalence in 2014. Cancer Res Treat. 2017:49(2):292-305.

2. Prostate Cancer Trialists' Collaborative Group. Maximum androgen blockade in advanced prostate cancer: an overview of the randomised trials. Lancet. 2000:355(9214):1491-8.

3. Petrylak DP, Tangen CM, Hussain MH, Lara PN Jr, Jones JA, Taplin ME, et al. Docetaxel and estramustine compared with mitoxantrone and prednisone for advanced refractory prostate cancer. N Engl J Med. 2004;351(15):1513-20.

4. Tannock IF, de Wit R, Berry WR, Horti J, Pluzanska A, Chi KN, et al. Docetaxel plus prednisone or mitoxantrone plus prednisone for advanced prostate cancer. N Engl J Med. 2004;351(15):1502-12.

5. Joly F, Tannock IF. Chemotherapy for patients with hormone-refractory prostate cancer. Ann Oncol. 2004;15(11):1582-4.

6. Berthold DR, Pond GR, Soban F, de Wit R, Eisenberger M, Tannock IF. Docetaxel plus prednisone or mitoxantrone plus prednisone for advanced prostate cancer: updated survival in the TAX 327 study. J Clin Oncol. 2008; 26(2):242-5. 
7. Shimazui T, Kawai K, Miyanaga N, Kojima T, Sekido N, Hinotsu S, et al. Threeweekly docetaxel with prednisone is feasible for Japanese patients with hormone-refractory prostate cancer: a retrospective comparative study with weekly docetaxel alone. Jpn J Clin Oncol. 2007;37(8):603-8.

8. Taguchi T, Furue H, Niitani H, Ishitani K, Kanamaru R, Hasegawa K, et al. Phase I clinical trial of RP 56976 (docetaxel) a new anticancer drug. Gan To Kagaku Ryoho. 1994;21(12):1997-2005.

9. Lee JL, Kim JE, Ahn JH, Lee DH, Lee J, Kim CS, et al. Efficacy and safety of docetaxel plus prednisolone chemotherapy for metastatic hormonerefractory prostate adenocarcinoma: single institutional study in Korea. Cancer Res Treat. 2010;42(1):12-7.

10. Kellokumpu-Lehtinen $P L$, Harmenberg $U$, Joensuu T, McDermott $R$, Hervonen P, Ginman C, et al. 2-weekly versus 3-weekly docetaxel to treat castration-resistant advanced prostate cancer: a randomised, phase 3 trial. Lancet Oncol. 2013;14(2):117-24.

11. Kim HS, Lee JY, Lee SJ, Lim HY, Sung HH, Jeon HG, et al. A retrospective feasibility study of biweekly, reduced-dose docetaxel in Asian patients with castrate-resistant, metastatic prostate cancer. BMC Urol. 2017;17(1):63.

12. Millikan RE, Wen S, Pagliaro LC, Brown MA, Moomey B, Do KA, et al. Phase III trial of androgen ablation with or without three cycles of systemic chemotherapy for advanced prostate cancer. J Clin Oncol. 2008;26(36): 5936-42.

13. Sweeney CJ, Chen YH, Carducci M, Liu G, Jarrard DF, Eisenberger M, et al. Chemohormonal therapy in metastatic hormone-sensitive prostate Cancer. N Engl J Med. 2015;373(8):737-46.

14. Gravis G, Boher JM, Joly F, Soulie M, Albiges L, Priou F, et al. Androgen deprivation therapy (ADT) plus docetaxel versus ADT alone in metastatic non castrate prostate Cancer: impact of metastatic burden and long-term survival analysis of the randomized phase 3 GETUG-AFU15 trial. Eur Urol. 2016:70(2):256-62.

15. James ND, Sydes MR, Clarke NW, Mason MD, Dearnaley DP, Spears MR, et al. Addition of docetaxel, zoledronic acid, or both to first-line long-term hormone therapy in prostate cancer (STAMPEDE): survival results from an adaptive, multiarm, multistage, platform randomised controlled trial. Lancet. 2016:387(10024):1163-77.

16. Parker C, Gillessen S, Heidenreich A, Horwich A, Committee EG. Cancer of the prostate: ESMO clinical practice guidelines for diagnosis, treatment and follow-up. Ann Oncol. 2015;26(Suppl 5):v69-77.

17. Gillessen S, Attard G, Beer TM, Beltran H, Bossi A, Bristow R, et al. Management of Patients with advanced prostate Cancer: the report of the advanced prostate Cancer consensus conference APCCC 2017. Eur Urol. 2018;73(2): 178-211.

18. Scher HI, Halabi S, Tannock I, Morris M, Sternberg CN, Carducci MA, et al. Design and end points of clinical trials for patients with progressive prostate cancer and castrate levels of testosterone: recommendations of the prostate Cancer clinical trials working group. J Clin Oncol. 2008;26(7):1148-59.

19. Droz JP, Aapro M, Balducci L, Boyle H, Van den Broeck T, Cathcart P, et al. Management of prostate cancer in older patients: updated recommendations of a working group of the International Society of Geriatric Oncology. Lancet Oncol. 2014:15:e404-14.

Ready to submit your research? Choose BMC and benefit from:

- fast, convenient online submission

- thorough peer review by experienced researchers in your field

- rapid publication on acceptance

- support for research data, including large and complex data types

- gold Open Access which fosters wider collaboration and increased citations

- maximum visibility for your research: over $100 \mathrm{M}$ website views per year

At $\mathrm{BMC}$, research is always in progress.

Learn more biomedcentral.com/submissions 